\title{
Diversity with a difference
}

\author{
The Natural History of \\ Madagascar \\ edited by Steven M. Goodman \\ \& Jonathan P. Benstead \\ University of Chicago Press: 2004. 1,760 pp.

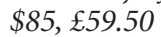

\section{Tim Flannery}

Madagascar is perhaps the strangest place on Earth - an island where things can seem beguilingly familiar but on closer inspection take on an utterly alien aspect. Some of Madagascar's spiny insectivores known as tenrecs look like hedgehogs, but live very unhedgehog-like lives, anointing themselves with toxic chemicals and communicating by means of an organ of stridulation, from which eerie tones emerge, caused by the rattling of quills. Even evolution on the island seems to have occurred in the wrong order: elsewhere, rainforests commonly represent the ancestral (early Tertiary) environment, yet Madagascar's most venerable vegetation is its semi-arid, baobab-dominated scrubland.

Until 90 million years ago, Madagascar was part of the supercontinent of Gondwana, and its fossil record, much of it only recently revealed, is highly surprising. Palaeontological explorations by John Flynn and his team uncovered rich deposits dating to the mid-Jurassic (about 160 million years ago) that contain the remains of the world's oldest advanced (tribosphenic) mammal. And David Krause and co-workers discovered that, 70 million years ago, marsupials and archaic (non-tribosphenic) mammals shared the newly isolated island with an astonishing diversity of dinosaurs and crocodiles, including a herbivorous crocodilian with flattened teeth and a turtlelike skull.

All these creatures seem to have become extinct without leaving descendants on the island - the ancestors of Madagascar's lemurs and most other living mammals (as well as many flying invertebrates and birds) all arrived by sea during the past 60 million years. There are, however, some truly ancient endemics, whose ancestors have survived in situ since the age of dinosaurs - including reptiles such as the freshwater turtle Erymnochelys madagascariensis, whose nearest relatives are found in South America.

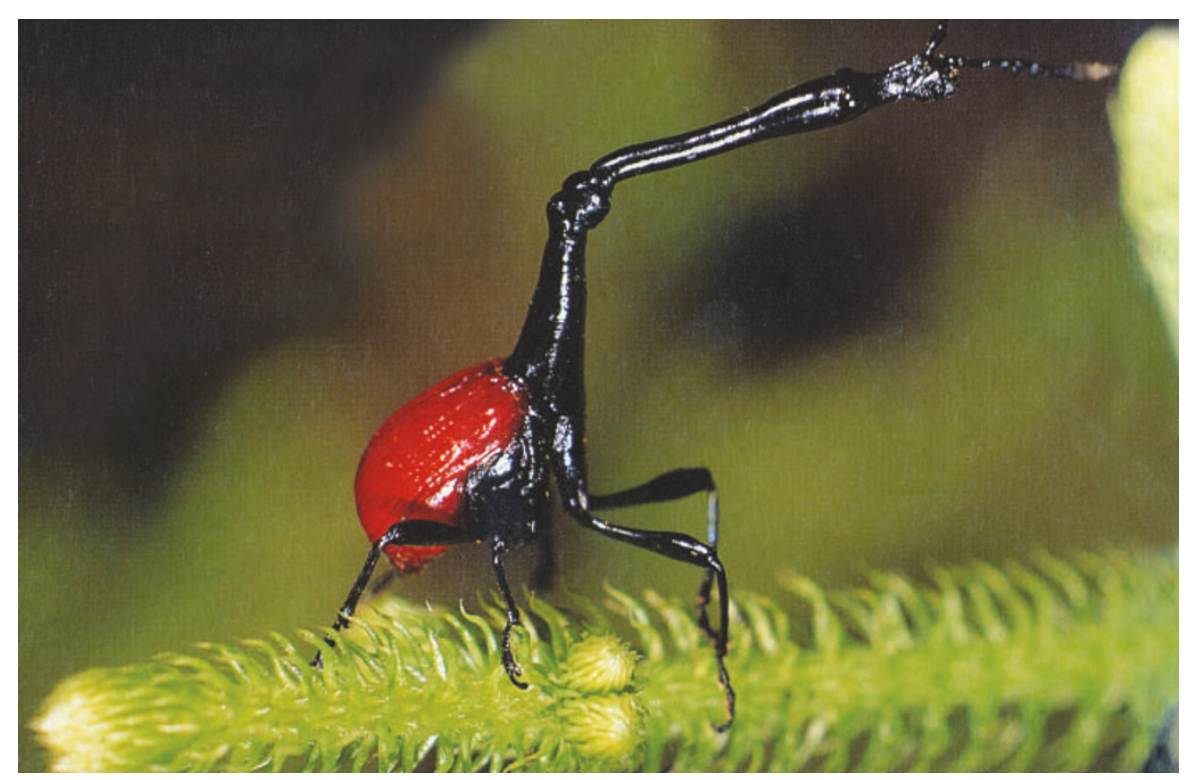

The giraffe-necked weevil (Trachelophorus giraffa) is one of Madagascar's myriad bizarre creatures.

As exciting as Madagascar's biodiversity is today, the first humans to step ashore encountered an even more extraordinary world. The date is not definitely known, although it may have been afterWilliam the Conqueror crossed the English Channel in 1066. Amazingly, the settlers did not come from nearby Africa, but from southeast Asia. Those lucky pioneers would have seen, among other wonders, the world's largest bird (the elephant bird Aepyornis maximus), a lemur the size of a gorilla, a creature known as Plesiorycteropus (which is so odd that its relationships cannot be definitively established), giant tortoises and pygmy hippos. By the fourteenth century, most of these were extinct, and today the largest of Madagascar's native landbased animals weighs less than 10 kilograms.

For those who are serious about getting to know this fascinating island, there is no better resource than The Natural History of Madagascar. It is the closest thing to a compre-
history of the region ever produced. Containing detailed accounts of flora, fauna, human ecology and the marine environment, even obscure groups such as the freshwater diatoms and springtails gain some coverage, although puzzlingly there is no chapter on the island's gymnosperms (pines and their relatives).

The extensive tabulated lists accompanying many of the systematic accounts will be invaluable to specialists, as will the exhaustive references that complete each major section. Such a book could have been dull, but this volume is rescued by the inherent interest of creatures such as Dracula ants, whose queens subsist by sucking the blood of their larvae, and tales of scientific discovery, such as the finding in 1994 of the island's only species of Winteraceae (a family of primitive flowering plants), which was last seen in 1909.

The book also makes it clear that Madagascar's biodiversity is under severe threat. In their chapter on freshwater fishes, John Sparks and Melanie Stiassny note that neither had ever "witnessed anything surpassing the degree and extent of environmental degradation in Madagascar", and that "it is likely too late to save all but small remnants" of the island's unique fishes. This is particularly tragic given that Madagascar's fish fauna is highly endemic and that some of its fishes are ancient relatives of groups that today dominate elsewhere.

Despite such gloomy prognostications, The Natural History of Madagascar provides hope for a better future, as it warns of the disastrous losses to come and brims with innovative ideas about how to stave off the looming ecological catastrophe. The notion that seems to me to have particular merit is David Burney's suggestion that ostriches and the Aldabran giant tortoise (which may be the same species as Madagascar's extinct giant tortoise) be returned to the Madagascan grasslands, where they might help to control fire, offer a source of meat and act as a focus for tourism.

Yet the most encouraging thing about this book is surely its large number of Malagasy contributors, for it bespeaks a growing body of local expertise in biological sciences and conservation, without which any attempt to save the biodiversity of the most extraordinary place on Earth would be doomed.

Tim Flannery is director of the South Australian Museum, North Terrace, Adelaide, South

Australia 5000, Australia. 